\title{
Advancing Plastic Recycling by Wet-Mechanical Processing of Mixed Waste Fractions
}

\author{
Daniel Schwabl ${ }^{1, * \mathbb{D}}$, Markus Bauer ${ }^{1}$ and Markus Lehner ${ }^{2}$ \\ 1 Circulyzer GmbH, Peter-Tunner-Straße 19, 8700 Leoben, Austria; office@circulyzer.at \\ 2 Montanuniversitaet Leoben, Chair of Process Technology and Environmental Protection, \\ Franz-Josef-Straße 18, 8700 Leoben, Austria; markus.lehner@unileoben.ac.at \\ * Correspondence: daniel.schwabl@circulyzer.at
}

Citation: Schwabl, D.; Bauer, M.;

Lehner, M. Advancing Plastic Recycling by Wet-Mechanical Processing of Mixed Waste Fractions. Processes 2021, 9, 493. https:// doi.org/10.3390/pr9030493

Academic Editors: Daniel Vollprecht and Renato Sarc

Received: 30 November 2020

Accepted: 5 March 2021

Published: 9 March 2021

Publisher's Note: MDPI stays neutral with regard to jurisdictional claims in published maps and institutional affiliations.

Copyright: (c) 2021 by the authors. Licensee MDPI, Basel, Switzerland. This article is an open access article distributed under the terms and conditions of the Creative Commons Attribution (CC BY) license (https:// creativecommons.org/licenses/by/ $4.0 /)$.

\begin{abstract}
In this paper, an arc was drawn over ten years of research activities from three chairs of the Montanuniversitaet Leoben, as well as industrial partners. The superior objective of this research effort was to develop a wet-mechanical process for the recovery of polyolefin concentrates (90 $\mathrm{wt} \%$ polyolefins) from mixed waste fraction for use in chemical recycling and to advance this new technology to commercial maturity. As a bridge technology, it would close the gap between state-of-the-art dry processing of mixed plastic waste materials and chemical plastic recycling via thermo-chemical conversion. The methods used were mainly tested in a lab-scale plant with a throughput capacity of 50 to $200 \mathrm{~kg} / \mathrm{h}$ depending on the bulk density of the used feedstock. Further studies for the treatment and usage of the main products and by-products, as well as chemical analyses of them, were completed during the investigation. Within these series of tests, polyolefin concentrates, which satisfied the requirements for chemical recycling, could be recovered. With these data, a concept for an industrial pilot plant was developed and evaluated from an economic point of view. According to this evaluation, the realization of such an industrial pilot plant can be recommended.
\end{abstract}

Keywords: plastics recycling; chemical recycling; wet-mechanical processing; polyolefins; circular economy

\section{Introduction}

\subsection{Plastic Recycling in Europe}

The report "Plastics Europe 2019" [1] states that 4-6\% of the global petroleum production was processed into polymer products, which amounted to $359 \mathrm{Mt}$ in 2018 . Of the global production of polymer products, $61.8 \mathrm{Mt}$ or $17 \%$ was related to Europe (In [1] Europe is defined as the 27 member states of the European Union as well as Norway, Great Britain, and Switzerland). The European demand for polymer products was 51.2 Mt in 2018. These polymers can be classified according to their usage or chemical polymer structure, see Tables 1 and 2.

Table 1. European polymer demand by application in 2018 [1].

\begin{tabular}{ccc}
\hline Application & Fraction (\%) & Period of Application \\
\hline Packaging & 39.9 & Days to weeks \\
Others (furniture, medical, etc.) & 20.8 & Months to years \\
Building and construction & 19.8 & Years to decades \\
Automotive & 9.9 & Years \\
Electrical and electronics & 6.2 & Years \\
Household, leisure and sport, and & 4.1 & Months to years \\
Agriculture & 3.4 & Weeks to months \\
\hline
\end{tabular}


Table 2. European polymer demand by chemical structure in 2018 [1].

\begin{tabular}{ccc}
\hline Polymer & Fraction (\%) & Exemplary Application \\
\hline Polyethylene (PE) & 29.7 & Bags, containers, toys, houseware \\
Polypropylene (PP) & 19.3 & Food packaging, automotive, pipes \\
Others & 19.0 & - \\
Polyvinylchloride (PVC) & 10.0 & Cable insulation, pipes, coverings \\
Polyurethanes (PUR) & 7.9 & Insulation foams, pillows, mattresses \\
Polyethylene terephthalate (PET) & 7.7 & Bottles for drinks and other liquids \\
Polystyrene (PS) & 6.4 & Packaging, insulations, electronics \\
\hline
\end{tabular}

Polyethylene and polypropylene (the so-called polyolefins) make up approximately $50 \%$ of Europe's polymer demand. Mainly used as packaging with a short period of use, they represent a disproportionate amount of the European waste streams. In 2018 these polymer wastes amounted to $29.1 \mathrm{Mt}$ [1], which were mostly collected as comparably heterogenous industrial or municipal mixed waste fractions. These mixed fractions are frequently unsuitable for mechanical recycling due to their heterogeneity and possible contaminations. Consequently, they are processed mechanically to be used as solid recovered fuels for energy recovery. This makes sense from an economic point of view because plastics have a comparable energy content to heating oil [2]. In countries with poorly developed waste management systems and without legislation demanding certain recycling quotas, substantial shares of plastic waste are still landfilled.

\subsection{Plastic Recycling in Austria}

In the last decade, some progress has been made to shift the treatment of mixed plastic wastes to a more circular economy approach. Whilst countries with poorly developed waste management systems are catching up, ruling countries like Austria, Germany, and Sweden have not been able to increase the proportion of polymer wastes in mechanical recycling. This trend can be seen in Table 3, which shows the data for Austria's plastic waste treatment.

Table 3. Treatment options of plastic waste fractions in Austria from 2006 to 2016 [1].

\begin{tabular}{ccccccc}
\hline \multirow{2}{*}{ Treatment Option } & \multicolumn{7}{c}{ Proportion of Polymer Wastes (\%) } \\
\cline { 2 - 7 } & $\mathbf{2 0 0 6}$ & $\mathbf{2 0 0 8}$ & $\mathbf{2 0 1 0}$ & $\mathbf{2 0 1 2}$ & $\mathbf{2 0 1 4}$ & $\mathbf{2 0 1 6}$ \\
\hline Mechanical recycling & 23 & 28 & 26 & 24 & 26 & 27 \\
Energy recovery & 69 & 65 & 71 & 75 & 73 & 72 \\
Landfilling & 8 & 7 & 3 & 1 & 1 & 1 \\
\hline
\end{tabular}

It seems there is a limit in current plastic waste treatment, especially regarding mechanical recycling. Different reasons for this have been discussed in numerous papers like "Mechanical and chemical recycling of solid waste" by K. Ragaert et al. [3]. The paper gives an overview of the most common types of solid plastic waste (SPW) by their origin (industry or consumer) as well as their possible further treatment according to significant properties like homogeneity, contamination, and composition. The overview emphasizes that most SPWs with known homogeneous composition and a low share of contamination are currently used for mechanical recycling. Such SPWs are predominantly so-called post-industrial (PI) plastics, such as fall-out products, waste from production (cuttings and trimmings), or residues from granulation [4]. In contrast, post-consumer (PC) plastics are more heavily mixed, degenerated by their usage, and contaminated with organic fractions like food waste or non-polymers like paper or metals [5]. Thus, their usage is limited to energy recovery.

When looking at the status of the Austrian waste management system, it can be noted that only about $13 \%$ of the SPWs in 2015 were of industrial or commercial origin [6] and would therefore be suitable for mechanical recycling without further treatment. 
These facts translate to the current state of the art in industrial plants for waste plastic recycling and processing in Austria. According to Bauer [7] and Kranzinger [6], of the $2.46 \mathrm{Mt}$ of waste streams containing PC and PI plastics in 2015, about $1.3 \mathrm{Mt}$ or $54 \%$ were used for energy recovery in waste incineration plants like Spittelau in Vienna. The remaining $46 \%$ were processed by four general types of industrial plants to recover plastics for recycling or to be used as solid recovered fuels of different quality grades. The required criteria according for these quality grades according to the Austrian Waste Management Act are summarized in Table 4 [8]. As they mainly focus on calorific value, particle size, and contamination, the processing in these four types of waste treatment plants will also focus on improving these parameters.

Table 4. Criteria for different quality grades of solid recovered fuel according to the Austrian waste management act [8].

\begin{tabular}{|c|c|c|c|c|c|c|}
\hline \multirow[b]{2}{*}{ Criteria } & \multicolumn{6}{|c|}{ Quality Grade of Solid Recovered Fuel } \\
\hline & $\begin{array}{l}\text { Power } \\
\text { Plant }\end{array}$ & $\begin{array}{c}\text { Low } \\
\text { (Grate } \\
\text { Combustion) }\end{array}$ & $\begin{array}{c}\text { Middle } \\
\text { (Fluidized-Bed } \\
\text { Combustion) }\end{array}$ & $\begin{array}{c}\text { High } \\
\text { (Calzinator } \\
\text { Combustion) }\end{array}$ & $\begin{array}{c}\text { Premium } \\
\text { (Primary } \\
\text { Combustion) }\end{array}$ & $\begin{array}{c}\text { Furnace } \\
\text { Combustion }\end{array}$ \\
\hline Calorific value (MJ/kg) & $11-15$ & $12-16$ & $12-16$ & $11-18$ & $22-25$ & $>25$ \\
\hline Particle size (mm) & $<50$ * & $<300$ & $<20-100$ & $<50-80$ & $<10-30$ & $<10 *$ \\
\hline Oversize share $(w \mathrm{t} \%)$ & 0 & $<3$ & $<2$ & $<1$ & $<1$ & 0 \\
\hline Impurities share (wt \%) & 1 & $<3$ & $<1$ & 0 & $<1$ & 0 \\
\hline Chlorine share $(\mathrm{wt} \%)$ & 1.5 & $<1$ & $<0.8$ & $<0.8$ & $<0.8$ & $<2$ \\
\hline Ash share $(w t \%)$ & 35 & - & $<20$ & - & $<10$ & $<10$ \\
\hline
\end{tabular}

\subsubsection{Packaging Waste Sorting Plants}

Packaging waste sorting plants processed about 225,000 tons [6] or 9\% of the Austrian waste streams containing PC and PI plastics in 2015. The comparably homogeneous feedstock is classified using screens or air separation to sort out big foil, which mainly consists of polyolefins. The smaller particles are then separated into $2 \mathrm{D}$ and $3 \mathrm{D}$ fractions, for instance, by ballistic separation. Flat and light particles like foils tend to accumulate in the $2 \mathrm{D}$ fraction whilst heavy plastics, metals, glass, or ceramics are discharged in the 3D fraction. The 2D particles are then separated by polymer type by a series of optical sorters. For the share intended for mechanical recycling (about 35\% of feedstock), additional purification steps can be implemented; the remaining plastics are used as high to premiumgrade solid recovered fuels. The 3D particles are treated by magnetic and eddy-current separation for metal recovery and then used as middle to low grade solid recovered fuels.

\subsubsection{Mechanical Waste Splitting Plants}

If mechanical waste splitting facilities for PI and PC plastics are added up, they accounted for 665,000 tons [6] or $27 \%$ of Austrian waste streams containing plastics in 2015. These plants are characterized by consecutive steps of comminution, classification, and metal recovery. When processing feedstocks that are rich in plastics and have lower moisture contents due to a low biogenic share, air classification and optical sorters are applied to recover middle to high-grade solid recovered fuels. Feedstocks containing higher contamination with biogenic material are treated by consecutive sieves and air classification to recover low to middle grad solid recovered fuels.

\subsubsection{Mechanical-Biological Treatment Plants}

Plastic waste streams with a significant biogenic share are treated in special mechanicalbiological plants. These plants processed about 240,000 tons [6] or 10\% of the Austrian waste streams containing plastics in 2015. Because of their high share of biogenic material like food, additional steps for biodegradation are added to the standard mechanical treatment. The waste material is fed into rotting tunnels, where it is moistened with water, ventilated with air, heated up to $40-50{ }^{\circ} \mathrm{C}$, and slowly rotated for days to weeks. As a result, the 
biogenic share is reduced, and low- to middle-grade solid recovered fuels, rotting gas for energy recovery, and a stabilized fraction for landfilling can be recovered.

\subsubsection{Solid Recovered Fuels Preparation Plants}

These plants are mainly for processing pretreated fractions from packaging waste sorting plants or other fractions considered as high-grade solid recovered fuels. In 2015 these plants processed about 123,000 tons [6] or 5\% of the Austrian waste streams containing plastics to generate high or premium-grade solid recovered fuels of consistent quality. Since these plants use a pretreated feedstock mainly consisting of plastics, only additional purification steps are conducted. Comminution, air classification, metal recovery by magnetic and eddy-current separation, and sometimes optical sorting to reduce the polyvinylchloride (PVC) share, and thus the chlorine load, are therefore implemented in these plants.

\subsection{Background of Research Activities}

To stimulate mechanical recycling of PI and PC plastics despite technical obstacles and most waste management systems being incineration centered, the European Union proposed a directive for a circular economy. According to this directive, the proportion of post-consumer plastics recycling shall be increased to $55 \%$ by 2025 [9]. To achieve this ambitious goal, maybe another technical approach, namely chemical recycling, could be a part of the solution.

A promising option to recycle more mixed waste plastics materially is feedstock or chemical recycling via thermal cracking or pyrolysis, i.e., connected to a refinery. Once liquefied by thermo-chemical conversion, the obtained hydrocarbon intermediates can be easily treated by diverse state-of-the-art refining processes according to their chemical and physical properties. At least they can be converted to ethylene and propylene, which can be further used to synthesize new polyethylene and polypropylene again. As a consequence, a plastic material cycle can be established which is capable of meeting the ever-growing challenge of material aging and accumulation of aggregates. However, decades of research and a multiplicity of failures indicate that plastic feedstock recycling in thermo-chemical conversion units needs adequately prepared feedstock of specified quality and high quantities.

Most of these failures were not due to technological limitations but rather for economic reasons. The feedstock of the required quality and quantity could not be obtained at prices that would enable a competitive process. Thus, a chemical recycling process-the so-called thermo-chemical conversion - with rather low-quality requirements for its feedstock (see Table 5) when comparing it to data of other known processes, according to Tukker [10] (see Table 6), was developed. This development was paired with research on a supplementary treatment process to ensure the long-term availability of the necessary feedstock.

Table 5. Feedstock requirements for thermo-chemical conversion [11].

\begin{tabular}{cc}
\hline Parameter & Requirement \\
\hline Particle size $(\mathrm{mm})$ & $<30-40$ \\
Bulk density $\left(\mathrm{kg} / \mathrm{m}^{3}\right)$ & $50-100$ \\
Calorific vale $(\mathrm{MJ} / \mathrm{kg})$ & $>30$ \\
Polyolefin share $(\mathrm{wt} \%)$ & $>90$ \\
Impurity share $(\mathrm{wt} \%)$ & $<10$ \\
Moisture $(\mathrm{wt} \%)$ & $<20$ \\
Halogen share $(\mathrm{wt} \%)$ & $<2$ \\
\hline
\end{tabular}


Table 6. Feedstock requirements for different chemical recycling processes [10].

\begin{tabular}{|c|c|c|c|c|c|}
\hline \multirow{2}{*}{ Parameter } & \multicolumn{5}{|c|}{ Feedstock Requirements } \\
\hline & Texaco $^{1}$ & Polymer-Cracking $^{2}$ & BASF $^{3}$ & Veba Combi ${ }^{4}$ & $\mathrm{SVZ}^{5}$ \\
\hline \multicolumn{6}{|l|}{ Mechanical Parameters } \\
\hline Particle size (mm) & $<10$ & $20-1$ & - & $<10$ & $80-20$ \\
\hline Fines share $(<250 \mu \mathrm{m})(\mathrm{wt} \%)$ & $<1$ & $<1$ & - & - & - \\
\hline Bulk density $\left(\mathrm{kg} / \mathrm{m}^{3}\right)$ & $>100$ & $400-300$ & - & $>300$ & - \\
\hline Moisture (wt\%) & $<5$ & $<1$ & - & $<1$ & - \\
\hline Ash share (wt $\%)$ & $<6$ & $5-2$ & - & - & $<10$ \\
\hline \multicolumn{6}{|l|}{ Plastics } \\
\hline Total plastic share $(\mathrm{wt} \%)$ & $>90$ & $95-90$ & - & $>90$ & - \\
\hline Polyolefin share $(\mathrm{wt} \%)$ & - & $80-70$ & - & - & - \\
\hline PVC share $(w t \%)$ & $<10$ & $4-2$ & $<5$ & $<4$ & $<2$ \\
\hline Polystyrene share $(w \mathrm{t} \%)$ & - & $30-15$ & - & - & - \\
\hline PET share $(w t \%)$ & - & $5-3$ & - & - & - \\
\hline \multicolumn{6}{|l|}{ Impurities } \\
\hline Metal share (wt $\%)$ & $<1$ & $<1$ & - & $<1$ & - \\
\hline Paper share $(w t \%)$ & $<10$ & - & - & - & - \\
\hline
\end{tabular}

${ }^{1}$ Texaco Gasification Process; ${ }^{2}$ Polymer Cracking Process; ${ }^{3}$ BASF (Badische Anilin- \& Soda-Fabrik) Conversion Process; ${ }^{4}$ Veba Combi Cracking Process; ${ }^{5}$ SVZ (Sekundärrohstoff-Verwertungszentrum Schwarze Pumpe GmbH) Gasification Process.

This was the starting point for ten years of interdisciplinary research activities. The Chairs for Process Technology and Industrial Environmental Protection, Mineral Processing and Waste Processing Technology and Waste Management at Montanuniversitaet Leoben, as well as industrial partners, tried to develop, investigate, and optimize such a novel treatment process for mixed waste plastics. This treatment process should close the gap between the already existing dry mechanic processing and a thermo-chemical conversion in a refinery.

\section{Materials and Methods}

2.1. Feedstock

A broad variety of waste streams containing PC as well as PI plastics were taken into consideration as potential feedstock. According to the Austrian waste management plan 33, waste code numbers of such waste streams could be identified. To narrow them down, three criteria were set to determine whether a waste stream could potentially serve as feedstock:

1. The waste stream must be non-hazardous

2. The waste stream must have a share of polyolefins of at least $20 \mathrm{wt} \%$

3. The waste stream must provide a mass flow of at least 20,000 $t$ per year in Austria (except material from landfill mining)

With these criteria, 16 waste code numbers could be identified as promising feedstock, which were assorted into 6 feedstock groups: plastic foils, plastic containers, lightweight packaging, substitute fuels, rejects from paper recycling, and landfill mining. The latter feedstock was added due to its environmental importance (with an estimated $2.2 \mathrm{Mt}$ in Austrian landfills [12]) even though no mass flow per year, as well as no share of polyolefins, could be specified. A detailed table of these feedstocks can be found in [12].

Samples of these 6 groups were collected in different Austrian waste processing facilities and examined for their suitability. By gathering additional data from waste companies, treatment facilities, and literature and combining them with the results of examinations, a review of the total polyolefin-rich waste streams emerging in the Austrian waste system could be achieved. According to Kranzinger [6], as can be seen in Table 7, more than half of the Austrian waste polyolefins were of municipal origin. Additionally, 
considerable amounts of industrial and commercial sources representing at least 430,000 tons per year in 2015 [6] could be used. (Potential feedstock from landfill mining was not taken into consideration for this estimation.) The most apparent difference of these sources is their polyolefin share which is comparatively high for industrial wastes. Of these 430,000 tons, only $60,000(\sim 15 \%)$ are mechanically recycled, according to this analysis.

Table 7. Available post-consumer polyolefins in Austria in 2015 [6].

\begin{tabular}{cccc}
\hline Source & Total Amount (t/y) & Polyolefins (t/y) & Polyolefin Share (wt\%) \\
\hline Municipal & $1,656,600$ & 238,100 & 14 \\
Commercial & 600,000 & 84,000 & 14 \\
Industrial & 199,600 & 106,900 & 54 \\
\hline
\end{tabular}

t/y: tons per year.

Samples of different waste streams (solid recovered fuels, mixed plastics, rejects from paper recycling, landfill mining, etc.) were prepared for treatment in the erected lab-scale plant by shredding them to a particle size of $<20 \mathrm{~mm}$ because of the large number of input materials from different waste processing plants all over Austria three feedstocks were chosen as representatives and are further discussed in this paper.

Pictures of these three samples representing a feedstock with a high (A), middle (B), and low (C) share of polyolefins can be seen in Figure 1. Table 8 depicts their determined average mass fraction of polyolefins $\left(\overline{\mathrm{w}}_{\mathrm{PO}}\right)$ and the eightieth percentile of the particle size distribution; particle size of $80 \%$ cumulative passing $\left(\mathrm{p}_{80}\right)$.

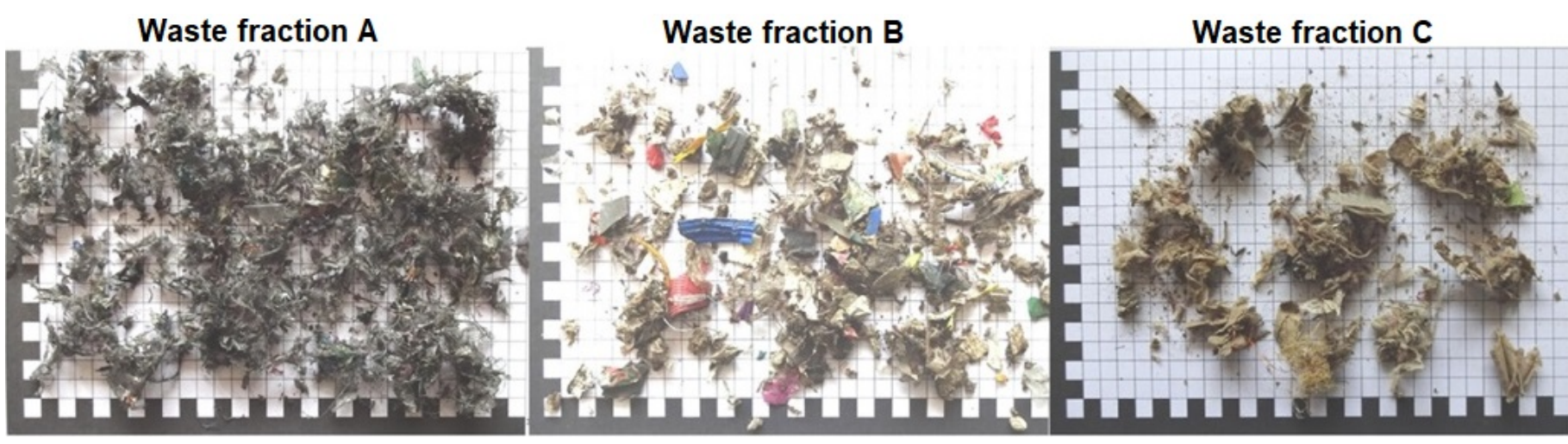

Figure 1. Waste fraction A, B, and C (left to right) [13] (Reproduced with permission from Schwabl D.; Proceedings of tenth "Recycling und Rohstoffe" Conference published by TK-Verlag, Berlin, 2017).

Table 8. Parameters of representing feedstock samples for high (A), middle (B), and low (C) share of polyolefins [13].

\begin{tabular}{ccccc}
\hline Waste Fraction & Origin & Composition & $\mathbf{p}_{\mathbf{8 0}}(\mathbf{m m})$ & $\mathbf{w}_{\mathbf{P O}}(\mathbf{w t} \%)$ \\
\hline A & Lightweight packaging & 2D and 3D plastics with superficial & 7.8 & 55.8 \\
B & Middle-grade & 2D and 3D plastics, polystyrene, wood, and & 9.8 & 34.4 \\
C & substitute fuels & paper textiles & 10.9 & 11.8 \\
\hline
\end{tabular}

$\mathrm{p}_{80}$ : particle size of $80 \%$ cumulative passing; $\overline{\mathrm{w}}_{\mathrm{PO}}$ : average mass fraction of polyolefins.

\subsection{The Lab-Scale Plant}

A lab-scale plant was built to examine the possibility of recovering polyolefins from the determined feedstocks. The plant basically consisted of two core components, which each conducted a certain kind of density separation to recover a light (LF), middle (MF), and a heavy fraction (HF), as can be seen in Figure 2. 


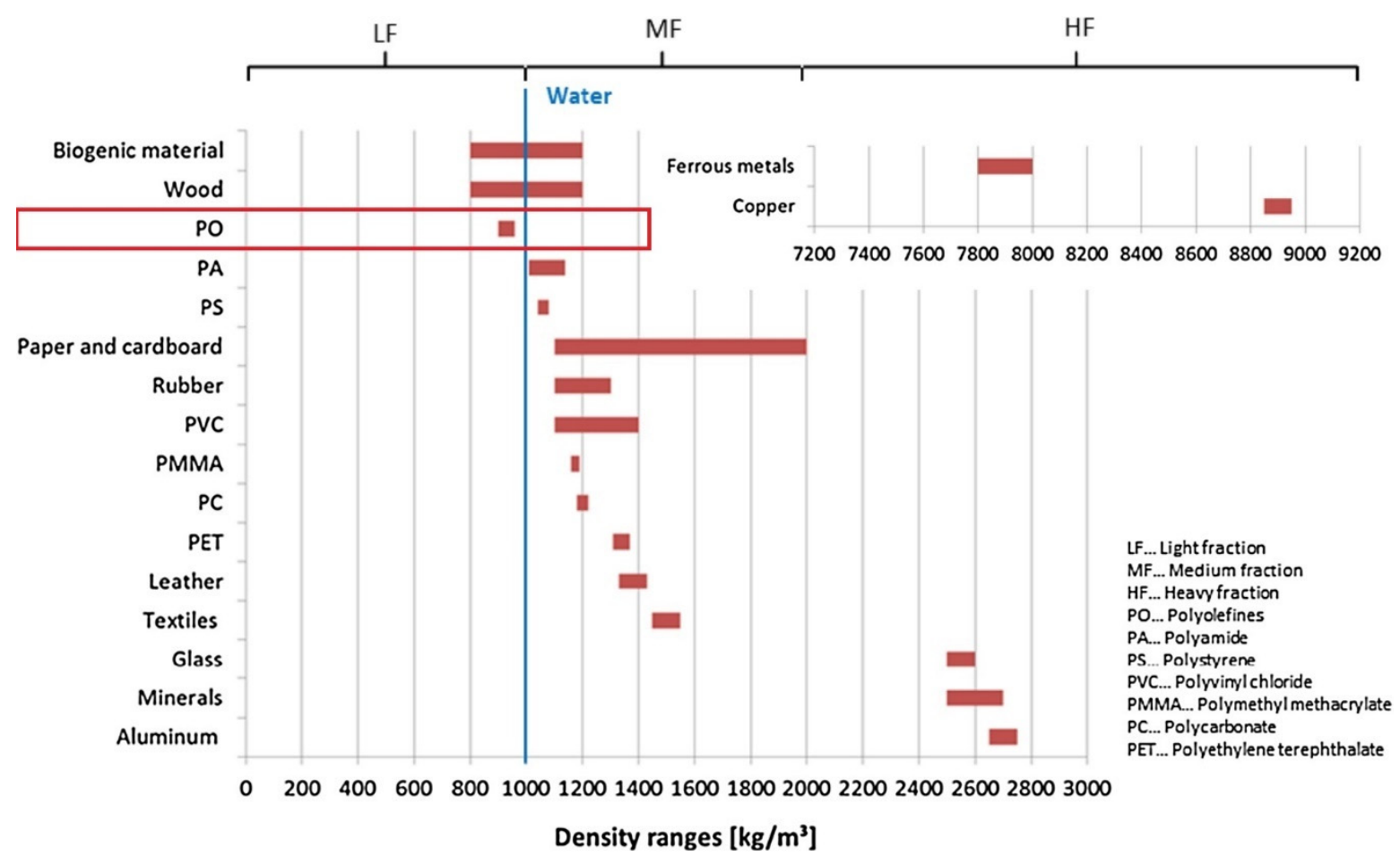

Figure 2. Density ranges of common components of mixed waste fractions and their respective product of the separation process [14].

\subsubsection{Jig}

The first separation step was conducted by a jig to partition heavy impurities like glass, metals, stones, and ceramics from light impurities and the contained plastics. The jig, as can be seen in Figure 3 on the left, which consisted of a stationary upper and movable lower tray. The former was equipped with a screen lining to collect the fed particles, and the latter executed an alternating up and down movement driven by an eccentric gear to generate a periodical upstream when filled with water. Consequently, the induced upstream scatters the particles in the bed and starts layering them according to their initial drop acceleration, which is mainly a function of particle size, shape, and density. In the case of considered post-consumer plastics, particle density is the dominant factor due to the plastics' huge density difference compared to other impurities. In the different density layers, the plastics concentrate in the upper and the impurities in the lower ones. Using a barrage, the plastics are transferred into the inter-fraction (IF) and the impurities into the heavy fraction (HF). Because the jig was constructed for mineral processing, it was suitable for abrasive materials and high throughputs. As a secondary effect, the particles of the IF are moistened and washed. This is beneficial to the second separation step due to the enhanced miscibility of these particles with the separation medium and the lower contamination of the used separation medium. 

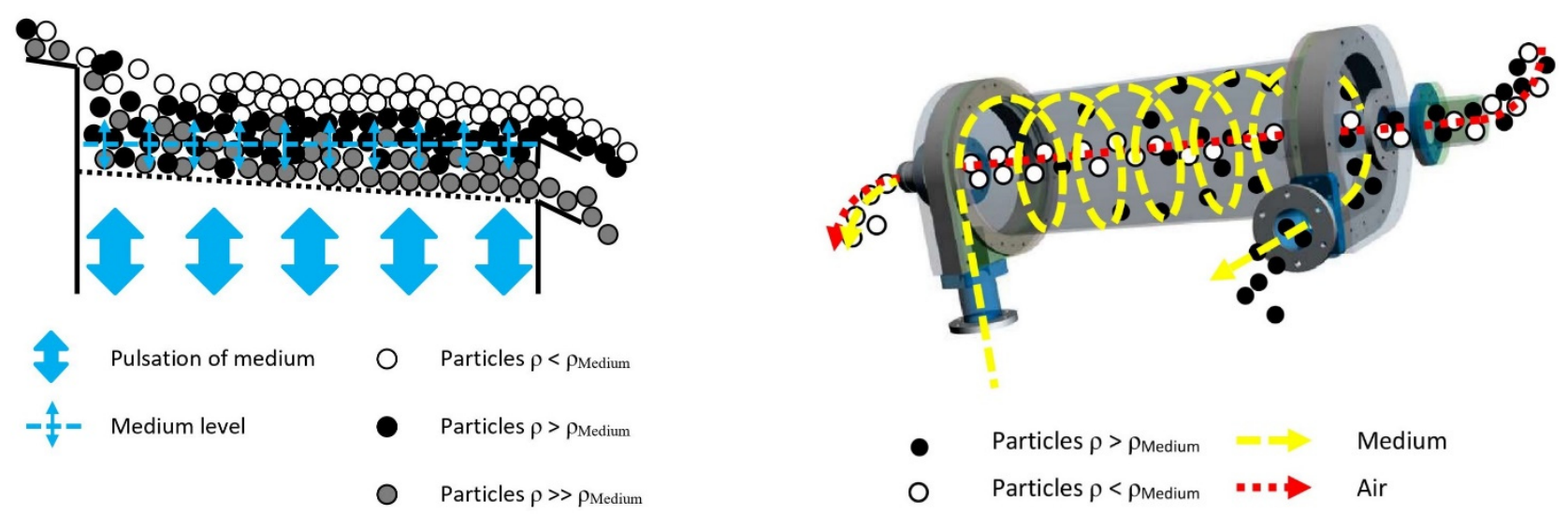

Figure 3. Function principle of the core components: Jig (left) and centrifugal force separator [13] (right) (Reproduced with permission from Schwabl D.; Proceedings of the tenth "Recycling und Rohstoffe" Conference published by TK-Verlag, Berlin, 2017).

\subsubsection{Centrifugal Force Separator}

In the second separation step, the polyolefins should be recovered from the IF, consisting basically of light impurities and mixed plastics. As can be seen in Figure 2, this can be done by density separation using water as a separation medium. A study of different density separation apparatuses [5] found a so-called centrifugal force separator (CFS) after the LarCoDeMS (Large Coal Dense Media Separation) -model, to be the most suitable for this step.

A CFS (as depicted in Figure 3, on the right) generally consists of an inclined cylinder with 4 tube-guided streams in and out of the separator. The feed material is separated by sink-/float-separation in a centrifugal field, thus having higher throughput than a sink-/float tank only using gravity. These centrifugal forces are induced by the separation medium, which is pumped into the separator tangentially at the lower end. Due to the shape of the CFS, the separation medium builds up a medium vortex with an air core and leaves the separator tangentially at the upper tangential outlet. The IF enters the separator axial from the upper central tube directly into the air core. The particles mix with the rotating separation medium, which induces centrifugal forces of about 15 times gravity. Particles with a higher density than the separation medium sink into the fluid and are dragged to the upper tangential outlet. There the particles exit the CFS as a middle fraction (MF) consisting of heavy plastics like polyethylene terephthalate (PET) or PVC and light impurities like paper and textiles. Particles with a density lower than the separation medium stay near the interface of the air core and the rotating fluid. Due to the inclination of the CFS, these particles are discharged with a small amount of the separation medium in the light fraction (LF), mostly consisting of polyolefins. The MF and LF are discharged onto separated compartments of a dewatering screen. The collected process water is stored in a basin and recirculated to the CFS.

\subsubsection{Function Principle of the Lab-Scale Plant}

The flow chart of the final construction of the lab-scale plant can be seen in Figure 4. As mentioned, the feed of mixed waste fractions must be shredded to a particle size of $20 \mathrm{~mm}$ or less to prevent plugging. The samples were fed to the jig via a vibrating feeder to guarantee a continuous material input stream and adjust its quantity. The feedstock sample was separated by density layering as mentioned above, and the HF and IF were discharged. Both fractions were dewatered afterward by the dewatering screen with a separate compartment for each fraction. 


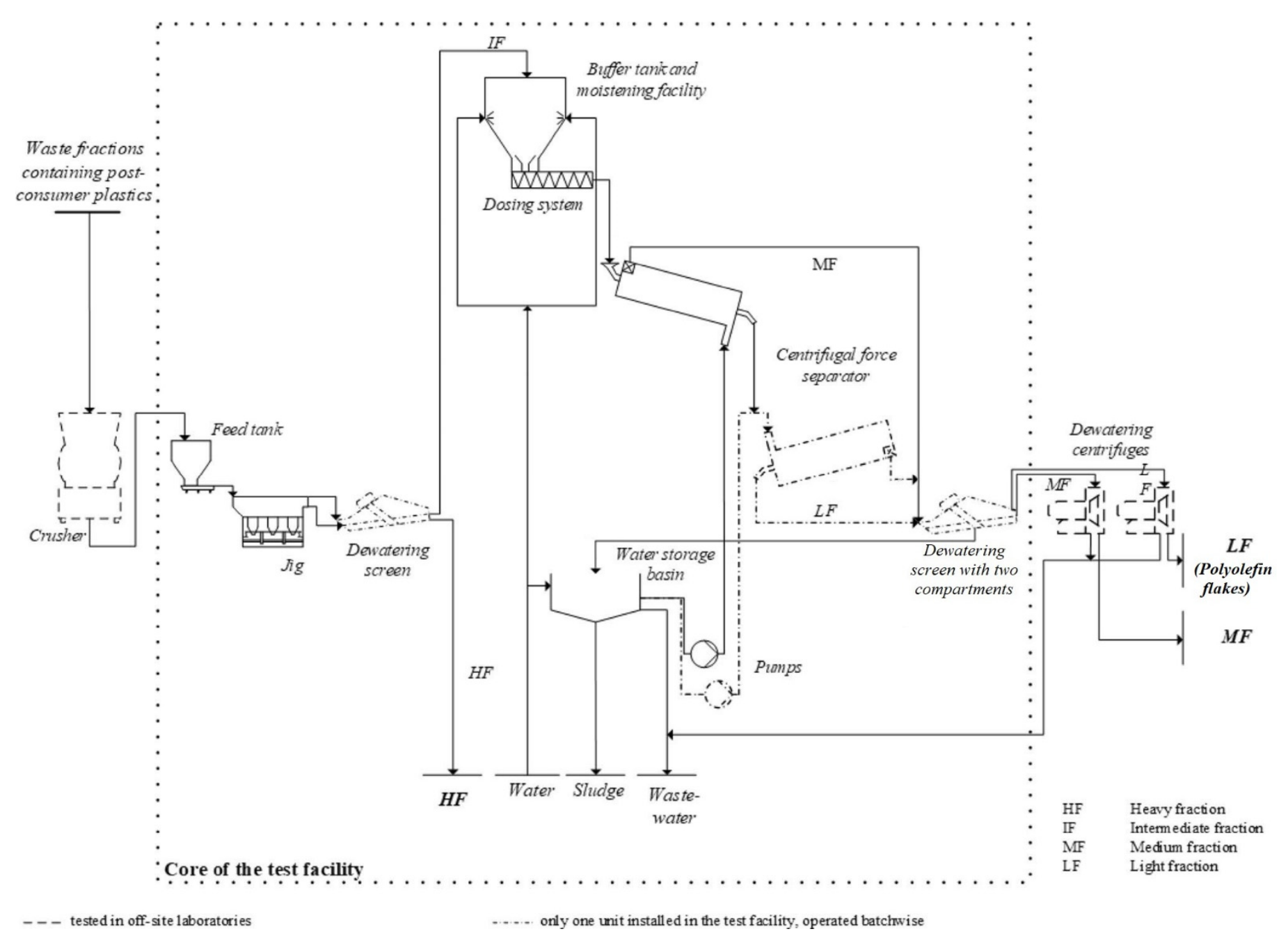

Figure 4. Flowchart of the lab-scale plant [14].

The lab-scale plant was only equipped with one water-circuit consisting of a pump with bypass control, a storage tank, and a dewatering screen. Thus, the jig and the CFS could not be operated in parallel. Consequently, after all the feedstocks had been processed by the jig, the IF was fed to the CFS. The CFS separated the MF and the LF, which were both again dewatered by the dewatering screen. If the desired share of polyolefins in the LF was not achieved, the generated fractions were processed multiple times in the CFS for further purification.

To summarize, the lab-scale plant can recover an HF fraction comprised of heavy impurities (glass, stones, ceramics, and metals), an MF (paper, rubber, and heavy plastics), and an LF (polyolefins) from different feedstock materials. The plant could process 50 to $200 \mathrm{~kg}$ of material per hour, depending on its bulk density. The operating parameters used for the jig and the CFS are summarized in Tables 9 and 10. These operating parameters were defined by preceding experiments $[15,16]$.

Table 9. Operating parameters of the jig.

\begin{tabular}{cc}
\hline Parameter & Setting \\
\hline Water pressure & $1 \mathrm{bar}$ \\
Water flow & $16 \mathrm{~m}^{3} / \mathrm{h}$ \\
Inclination of screen lining & $4^{\circ}$ \\
Lifting frequency & $120 \mathrm{~min}^{-1}$ \\
Lifting height & $20 \mathrm{~mm}$ \\
\hline
\end{tabular}


Table 10. Operating parameters of the centrifugal force separator (CFS).

\begin{tabular}{cc}
\hline Parameter & Setting \\
\hline Water pressure & $0.2 \mathrm{bar}$ \\
Water flow & $25 \mathrm{~m}^{3} / \mathrm{h}$ \\
Inclination of CFS & $40^{\circ}$ \\
\hline
\end{tabular}

\section{Results}

\subsection{Experimental Results}

In the main test series regarding the recovery of polyolefins from different feedstocks, up to $50 \mathrm{~kg}$ of total input materials were processed in the lab-scale plant. The samples were processed as described in Section 2.2.3, with the exception that the LF was processed a second time with the CFS for further purification. All recovered fractions were examined by sink-/float-separation and drying at $80{ }^{\circ} \mathrm{C}$ to determine the share of polyolefins as well as the water content subsequently. Further samples of the main and by-products, as well as the process water, were examined for their pollution burden. Samples of the products were also analyzed chemically to figure out their calorific value. Further data from these analyses can be found in [14]. The data of the recovery of the polyolefins for the three representative samples are summarized in Table 11; a related flow chart can be seen in Figure 5. The results of the individual separation steps are shown in Tables 12-14.

Table 11. Mass fraction of feed $\left(\mathrm{w}_{\text {Feed }}\right)$, heavy $\left(\mathrm{w}_{\mathrm{HF}}\right)$, middle $\left(\mathrm{w}_{\mathrm{MF}}\right)$ and light fraction $\left(\mathrm{w}_{\mathrm{LF}}\right)$ and corresponding polyolefin fraction $\left(\mathrm{w}_{\mathrm{PO}}\right)$ of the test series at the lab-scale plant for feedstocks with a high (A), middle (B), and low (C) initial polyolefin share.

\begin{tabular}{|c|c|c|c|c|c|c|c|}
\hline \multirow{2}{*}{$\begin{array}{l}\text { Waste } \\
\text { Fraction }\end{array}$} & \multirow{2}{*}{$\begin{array}{l}\text { Feedstock }^{1} \\
\mathrm{w}_{\text {Feed }}\left(\mathrm{wt}^{\mathrm{T}} \%\right)\end{array}$} & \multicolumn{2}{|c|}{ Heavy Fraction } & \multicolumn{2}{|c|}{ Middle Fraction } & \multicolumn{2}{|c|}{ Light Fraction } \\
\hline & & $\begin{array}{c}w_{H F} \\
\left(w_{t} \%\right)\end{array}$ & $\begin{array}{c}w_{\text {PO }} \\
\text { (wt } \%)\end{array}$ & $\begin{array}{c}w_{M F} \\
(w t \%)\end{array}$ & $\begin{array}{c}w_{\text {PO }} \\
(w t \%)\end{array}$ & $\begin{array}{c}w_{L F} \\
(w t \%)\end{array}$ & $\begin{array}{c}w_{P O} \\
(w t \%)\end{array}$ \\
\hline A & 53.4 & 26.3 & 0.2 & 19.3 & 3.0 & 54.4 & 97.0 \\
\hline B & 31.5 & 49.6 & 0.5 & 18.0 & 5.1 & 32.5 & 93.4 \\
\hline $\mathrm{C}$ & 21.0 & 46.7 & 0.7 & 32.6 & 6.7 & 20.7 & 89.6 \\
\hline
\end{tabular}

${ }^{1} \mathrm{w}_{\mathrm{PO}}$ differs from Table 7 because of the difference in sample size and examination.

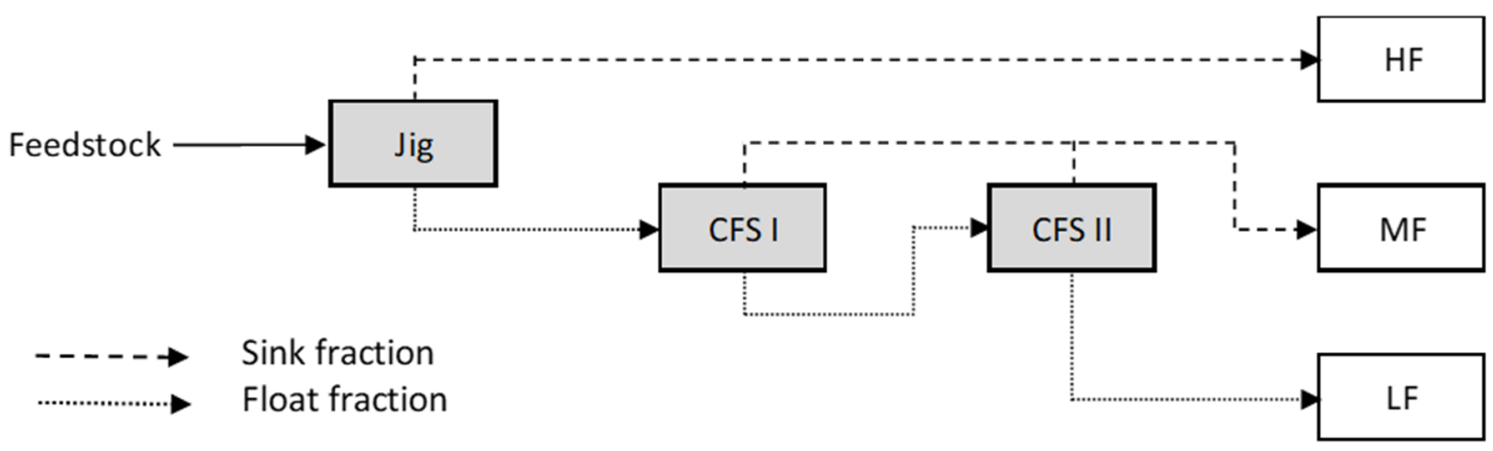

Figure 5. Flow chart of the conducted experiments; CFS I (centrifugal force separator's first pass), CFS II (centrifugal force separator's second pass), HF (heavy fraction), MF (middle fraction), and LF (light fraction). 
Table 12. Mass fraction of the feed $\left(\mathrm{w}_{\mathrm{Feed}}\right)$, heavy $\left(\mathrm{w}_{\mathrm{HF}}\right)$ and inter fraction $\left(\mathrm{w}_{\mathrm{IF}}\right)$ and corresponding polyolefin fraction $\left(\mathrm{w}_{\mathrm{PO}}\right)$ of the jig for feedstocks with high $(\mathrm{A})$, middle $(\mathrm{B})$, and low $(\mathrm{C})$ initial polyolefin share.

\begin{tabular}{cccccc}
\hline \multirow{2}{*}{$\begin{array}{c}\text { Waste } \\
\text { Fraction }\end{array}$} & Feedstock & \multicolumn{2}{c}{ Heavy Fraction } & \multicolumn{2}{c}{ Inter Fraction } \\
\cline { 2 - 6 } & $\left.\mathbf{w}_{\text {Feed }} \mathbf{( w t} \%\right)$ & $\left.\mathbf{w}_{\mathbf{H F}} \mathbf{( w t} \%\right)$ & $\left.\mathbf{w}_{\mathbf{P O}} \mathbf{( w t} \%\right)$ & $\mathbf{w}_{\mathbf{I F}} \mathbf{( w \mathbf { t } \% )}$ & $\mathbf{w}_{\mathbf{P O}} \mathbf{( w \mathbf { t } \% )}$ \\
\hline $\mathrm{A}$ & 53.4 & 26.3 & 0.2 & 73.7 & 72.4 \\
$\mathrm{~B}$ & 31.5 & 49.6 & 0.5 & 50.4 & 62.0 \\
$\mathrm{C}$ & 21.0 & 46.7 & 0.7 & 53.3 & 38.8 \\
\hline
\end{tabular}

${ }^{1}{ }_{\text {WPO }}$ differs from Table 7 because of difference in sample size and examination.

Table 13. Mass fraction of the inter $\left(\mathrm{w}_{\mathrm{IF}}\right)$, first middle $\left(\mathrm{w}_{\mathrm{MF}} \mathrm{I}\right)$ and first light fraction $\left(\mathrm{w}_{\mathrm{LF}} \mathrm{I}\right)$ and corresponding polyolefin fraction $\left(\mathrm{w}_{\mathrm{PO}}\right)$ of the first CFS for feedstocks with high (A), middle (B), and low (C) initial polyolefin share.

\begin{tabular}{|c|c|c|c|c|c|}
\hline \multirow{2}{*}{$\begin{array}{l}\text { Waste } \\
\text { Fraction }\end{array}$} & \multirow{2}{*}{$\begin{array}{c}\begin{array}{c}\text { Inter } \\
\text { Fraction }\end{array} \\
w_{\text {IF }}(w t \%)\end{array}$} & \multicolumn{2}{|c|}{ Middle Fraction I } & \multicolumn{2}{|c|}{ Light Fraction I } \\
\hline & & 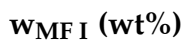 & $w_{P O}(w t \%)$ & $w_{\text {LF I }}(w t \%)$ & $w_{\text {PO }}(w t \%)$ \\
\hline A & 72.4 & 23.7 & 1.8 & 76.3 & 94.3 \\
\hline B & 62.0 & 5.5 & 9.9 & 94.5 & 65.0 \\
\hline $\mathrm{C}$ & 38.8 & 44.9 & 1.7 & 55.1 & 69.0 \\
\hline
\end{tabular}

Table 14. Mass fraction of the first light fraction $\left(\mathrm{w}_{\mathrm{LF}} \mathrm{I}\right)$, second middle ( $\left.\mathrm{w}_{\mathrm{MF}} \mathrm{II}\right)$ and second light fraction $\left(w_{\mathrm{LF}} \mathrm{II}\right)$ and corresponding polyolefin fraction $\left(\mathrm{w}_{\mathrm{PO}}\right)$ of the second CFS for feedstocks with high (A), middle (B), and low (C) initial polyolefin share.

\begin{tabular}{cccccc}
\hline \multirow{2}{*}{$\begin{array}{c}\text { Waste } \\
\text { Fraction }\end{array}$} & $\begin{array}{c}\text { Light } \\
\text { Fraction I }\end{array}$ & \multicolumn{2}{c}{ Middle Fraction II } & \multicolumn{2}{c}{ Light Fraction II } \\
\cline { 2 - 6 } & $\left.\mathbf{w}_{\text {LF I }} \mathbf{( w t} \%\right)$ & $\left.\mathbf{w}_{\text {MF II }} \mathbf{( w t} \%\right)$ & $\left.\mathbf{w}_{\text {PO }} \mathbf{( w t} \%\right)$ & $\left.\mathbf{w}_{\text {LF II }} \mathbf{( w t} \%\right)$ & $\mathbf{w}_{\text {PO }} \mathbf{( w t}$ \%) \\
\hline A & 94.3 & 3.5 & 13.2 & 96.7 & 97.0 \\
B & 65.0 & 31.9 & 4.3 & 68.2 & 93.3 \\
C & 69.0 & 29.5 & 19.8 & 70.5 & 89.6 \\
\hline
\end{tabular}

\subsection{Business Case}

As the results of the test series conducted with the lab-scale plant were very promising, a business case for an industrial pilot plant was designed and evaluated from an economic point of view. Knowing that former processes and plants failed due to economic rather than technical reasons, it was deemed vital to also focus on this challenge.

This evaluation was based on the experimental as well as additional data from literature [17-20] and interviews with experts from the waste processing industry and the Montanuniversitaet Leoben. The plant was designed for a throughput of 95,000 tons per year of mixed plastic waste with an average polyolefin share of $25.5 \mathrm{wt} \%$. Moreover, the estimation hypothesizes $3500 \mathrm{~h}$ of operation per year, producing 25,000 tons per year of a $90 \mathrm{wt} \%$ pure polyolefin flake. These and further basic parameters for the business case are depicted in Table 15. 
Table 15. Material and production parameters for the business case.

\begin{tabular}{ccc}
\hline & Feedstock & Polyolefin Flakes \\
\hline Mass stream (moist) & $95,000 \mathrm{t} / \mathrm{y}$ & $25,000 \mathrm{t} / \mathrm{y}$ \\
Water content & $27.1 \mathrm{t} / \mathrm{h}$ & $6.2 \mathrm{t} / \mathrm{h}$ \\
Mass stream (dry) & $15.0 \%$ & $15.0 \%$ \\
Polyolefin fraction & $82,500 \mathrm{t} / \mathrm{y}$ & $21,800 \mathrm{t} / \mathrm{y}$ \\
Mass fraction & $23.6 \mathrm{t} / \mathrm{h}$ & $6.2 \mathrm{t} / \mathrm{h}$ \\
& $25.5 \mathrm{wt} \%$ & $90.0 \mathrm{wt} \%$ \\
\hline
\end{tabular}

\subsubsection{Plant Design}

The basic design of the plant can be seen in Figure 6, which consisted of optional dry processing and wet-mechanical processing units. The dry processing unit was optional because, in many currently operating waste processing facilities, this part already exists (compare Section 1.2). Thus, the following discussion will focus only on the plant's wetmechanical processing section.

The incoming feedstock from the dry processing facility was placed into a dosing bunker to cope with material throughput fluctuations and to supply the plant with a steady mass stream of input material. The feedstock was firstly treated by a flip-flop screen to separate small particles as well as fine biological and mineral impurities. This fine fraction must be separated prior to the wet processing steps to reduce the formation of sludge. Afterward, the feedstock was processed by sensor-based sorting devices to eject the PVCplastics and decrease the chlorine burden. The latter processing step could be neglected if the feedstock is low in PVC. The data for the optical sorter was based on the findings in [21] can be seen in Table 16.
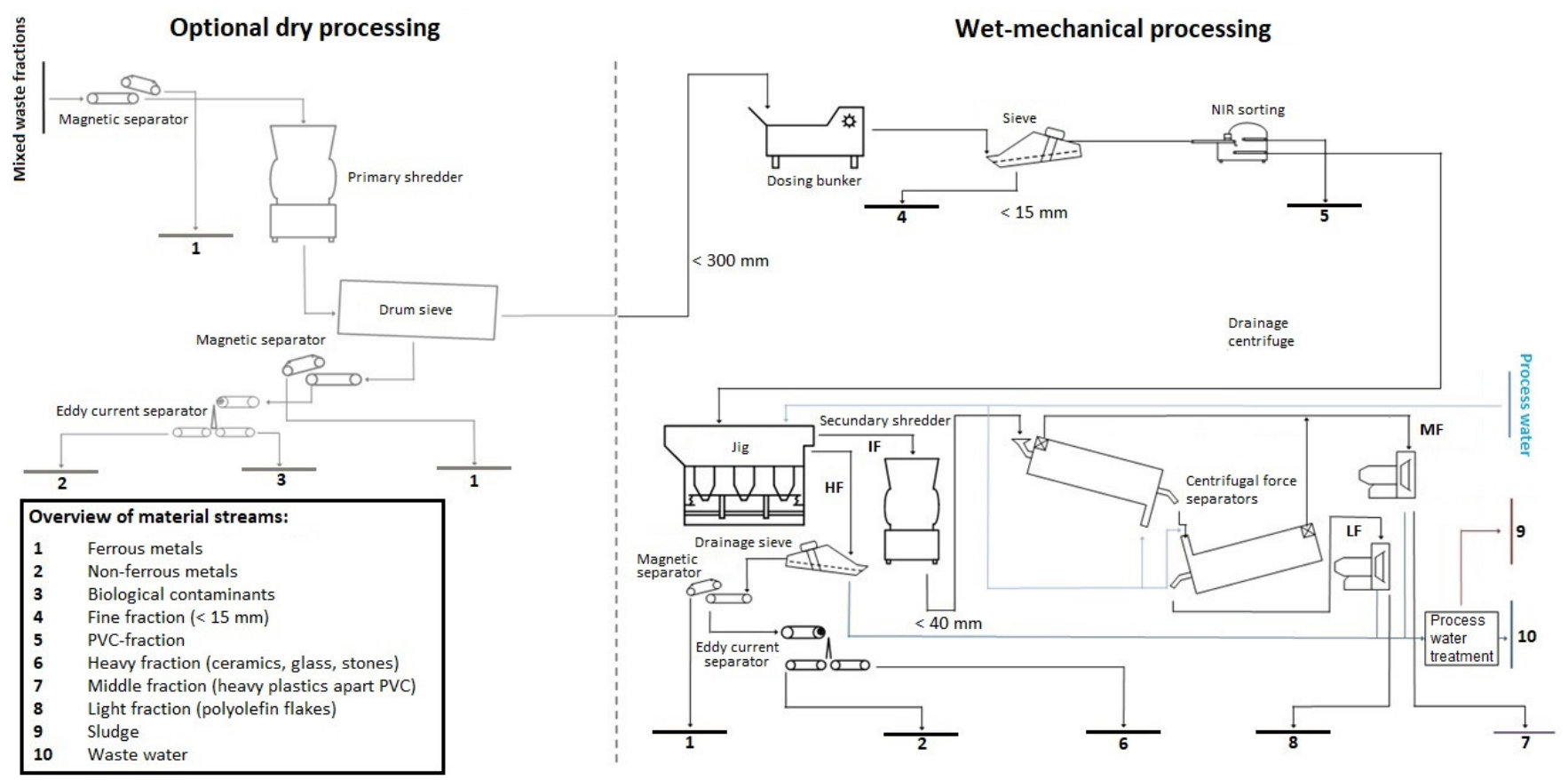

Figure 6. Flow chart of the designed industrial pilot plant [22] (Reproduced with permission from Schwabl D.; Proceedings of the fifteenth Recy and DepoTech-Conference; published by Chair of Waste Processing Technology and Waste Management (Montanuniversitaet Leoben; 2020). 
Table 16. Operating parameters of the assumed NIR (Near Infrared) sorter.

\begin{tabular}{cc}
\hline Type & Redwave Multiplexer \\
\hline Manufacturer & REDWAVE Waste GmbH \\
Wavelength & $1000-2500 \mathrm{~nm}$ \\
Light stripes & 64 \\
Scanning frequency & $50 \mathrm{~Hz}$ \\
Bandwidth & $1 \mathrm{~m}$ \\
\hline
\end{tabular}

After these separation steps, the wet-mechanical processing section consisting of a jig and two CFS was conducted. The preprocessed material was fed to the jig and separated into the HF and IF as outlined in Section 2.2.1. The HF was dewatered and passed through an additional magnetic and eddy current separator to recover ferrous and non-ferrous metals. The IF can be comminuted by a secondary shredding step to adapt the particle size before entering the CFS if necessary. In the CFS, the IF was separated into the LF and HF by density separation, as described in Section 2.2.2. The LF and MF were discharged into centrifuges and dewatered for further use.

All accruing process waters from dewatering were collected and treated by removing sludge and small particles before being recirculated. The process water of the CFS, as well as the watering of the MF and LF, were recirculated to a separate water circuit from the process water of the jig and the dewatering of the HF. This was due to the higher contamination with sludge and fine particles, which could otherwise shift the required density of the CFS' separation medium. Despite these measures, about $10 \%$ of the process water had to be replaced every hour.

\subsubsection{Economic Evaluation}

Following the described design, a plant with a throughput of 95,000 tons of mixed waste material per year would require a capital expenditure of about 4 million $€$ for the basic equipment (Table 17 shows their distribution to the different plant sections). As can be seen in Table 17, the dewatering and sensor-based sorting sections are the most expensive ones. To calculate the total capital expenditure, supplement factors were used to include costs for site area, buildings, pipes, measurements and controls, electrics, maintenance sites, construction, engineering, permits, and contingencies. According to M. Peters and K. Timmerhaus [20], these supplement factors sum up to $250 \%$ for such a combined dry and wet processing plant. Therefore the total capital expenditure could be estimated as 10 million $€$ if planned in a green-field scenario without additional water treatment.

Table 17. Capital expenditure for equipment per plant section.

\begin{tabular}{cc}
\hline Plant Section & Share of Equipment Costs (\%) \\
\hline Feeding & 1.8 \\
Sieving & 6.0 \\
Optical sorting & 31.3 \\
Jig and metal recovery & 10.0 \\
Secondary shredding & 10.8 \\
CFS and steel construction & 4.5 \\
Dewatering & 31.8 \\
Process water treatment & 4.0 \\
\hline
\end{tabular}

Knowing the total capital expenditure, it was possible to calculate the operational costs of the designed plant. If operated with two shifts for five days a week, these costs could be estimated to be $150 €$ per ton of feedstock or $37.5 €$ per ton of light fraction, respectively. The distribution of the operational costs per section can be seen in Table 18 . 
Table 18. Operational expenditure per section.

\begin{tabular}{cc}
\hline Section & Share of Operational Costs (\%) \\
\hline Plant depreciation & 35.2 \\
Water supply & 16.0 \\
Wastewater disposal & 13.6 \\
Maintenance & 8.1 \\
Staff & 17.3 \\
Energy & 9.8 \\
\hline
\end{tabular}

To determine if such a plant could be operated economically, the potential income and costs of the feedstock, main products, and by-products must be considered according to their expected mass shares. Table 19 shows this estimation according to income (negative sign), costs (positive sign), and the input and output streams' mass share. When these incomes and costs were summed according to the expected mass-share, an income of $54.1 €$ per ton of manufactured light fraction (output perspective) or of $205.5 €$ per ton of processed feedstock (input perspective) could be estimated.

Table 19. Income and costs of the feedstock and produced main and by-products.

\begin{tabular}{|c|c|c|c|c|c|}
\hline \multirow{2}{*}{ Material Stream } & \multirow{2}{*}{ Mass Share (\%) } & \multirow{2}{*}{ Usage } & \multicolumn{3}{|c|}{ Income/Costs $(€ / t)$ Per Ton of } \\
\hline & & & Material & Feedstock & LF \\
\hline Homogeneous residues & 23 & - & $-50^{1}$ & -11.5 & -43.7 \\
\hline Heterogeneous residues & 77 & - & $-75^{1}$ & -57.8 & -219.5 \\
\hline Ferrous metals & 3 & Mechanical recycling & $-105^{2}$ & -2.9 & -11.0 \\
\hline Non-ferrous metals & 2 & Mechanical recycling & $-550^{2}$ & -10.1 & -38.3 \\
\hline PVC-concentrate & 2 & Thermal disposal & $200^{3}$ & 3.7 & 13.9 \\
\hline Light fraction (LF) & 25 & Chemical recycling & $0^{4}$ & 0.0 & 0.0 \\
\hline Middle fraction (MF) & 51 & Energy recovery & $20^{5}$ & 10.3 & 39.0 \\
\hline Heavy fraction (HF) & 9 & Landfilling & $35^{5}$ & 3.2 & 12.2 \\
\hline Fine fraction & 5 & Thermal disposal & $80^{5}$ & 3.7 & 13.9 \\
\hline Sludge & 4 & Thermal disposal & $200^{3}$ & 7.3 & 27.9 \\
\hline Total & & & & -54.1 & -205.5 \\
\hline
\end{tabular}

${ }^{1}$ Deducted from common co-payments for secondary fuels; ${ }^{2}$ Deducted by interviews with scrap dealers and literature; ${ }^{3}$ Estimation for disposal in an incineration plant; ${ }^{4}$ Price is unknown and therefore set to $0 ;{ }^{5}$ Estimation by interviews with plant operators and literature [17-20].

By subtracting the operational costs of the income derived from the feedstock, byproducts, and main products, a possible profit of about $16.6 €$ per ton of feedstock or $55.5 €$ per ton of light fraction could be estimated. With these values, the amortization time of the designed plant could be assessed to be around six years using a discounted cash-flow method.

\section{Discussion}

Regarding the results of the test series conducted with the lab-scale plant, the recovery of a polyolefin-rich light fraction (LF) by using the combination of a jig and two centrifugal force separators could be accomplished. The polyolefin share of these LF was at least $90 \mathrm{wt} \%$ whether a feedstock with high ( $>50 \mathrm{wt} \%)$, middle (50-30 wt $\%)$, or low ( $>30 \mathrm{wt} \%)$ initial share was used. This indicates that the discussed process should be suitable to recover polyolefins from a broad variety of feedstocks for chemical recycling by thermochemical conversion. However, the initial polyolefin share will determine the resulting proportion of middle (MF) and heavy fractions (HFs). If only a single feedstock with consistent composition rather than a mixture is used, it should also be assessed if all three separations stages are necessary. For instance, feedstocks with very few heavy impurities like metals, glass, and stones would probably not require a jig. 
A plant using this technology and processing $95,000 \mathrm{t} / \mathrm{y}$ of mixed waste fractions features a capital expenditure of 10 million $€$ in a rough estimation for a green-field scenario. This capital expenditure could be reduced by 1.2 million $€$ if the processing step for sensorbased separation of PVC is not necessary. Additionally, about $30 \%$ of the capital expenditure could be cut if the plant was not built as a green-field scenario but as an expansion of an existing site. If the produced wastewater would exceed local wastewater treatment plant capacities, an additional 2 million $€$ would be needed for the construction of such a facility.

The operational costs of such a plant are mainly influenced by the number of operational hours changing the amount of specific material throughput. A continuous operation of the plant would, for example, cut the operational costs by $33 \%$. Of course, the biggest influence lies within the unknown income or costs of the light fraction. Hence it can be expected that the LF would generate a least a small revenue; this would substantially improve the economic basis of such a plant and, by that, lower the payback period from the calculated six to around four years.

With these combined results, the construction of such a pilot plant can, in principle, be recommended from an ecological as well as an economic point of view. However, a comprehensive assessment of the compositions and long-term availability of the intended feedstock will have to be conducted to get a sufficient basis for decision-making.

Author Contributions: Conceptualization, D.S. and M.B.; methodology, D.S. (experiments) and M.B. (plant design); validation, D.S. (plant design) and M.B. (experiments).; investigation D.S. (experiments) and M.B. (plant design); data curation D.S. (experiments) and M.B. (plant design); writing-original draft preparation D.S.; writing-review and editing M.B. and M.L.; visualization D.S. (experiments) and M.B. (plant design).; supervision M.B. and M.L.; project administration D.S.; funding acquisition M.B. and M.L. All authors have read and agreed to the published version of the manuscript.

Funding: This research was funded by the Österreichische Forschungsförderungsgesellschaft (FFG), grant number 844713 and 866712 , and by OMV (Österreichische Mineralölverwaltung) Refining and Marketing $\mathrm{GmbH}$.

Institutional Review Board Statement: Not applicable.

Informed Consent Statement: Not applicable.

Data Availability Statement: The data presented in this study are available on request from the corresponding author. The data are not publicly available due to their economic utilization in the start-up company of the corresponding author.

Acknowledgments: We would like to thank the teams of the chairs for Process Technology and Industrial Environmental Protection, Mineral Processing and Waste Processing Technology and Waste Management at Montanuniversitaet Leoben for their support during ten years of research. We thank the three heads of the chairs, Markus Lehner, Helmut Flachberger, and Roland Pomberger, as well as our long-time co-researcher Lukas Kranzinger. We also thank Wolfgang Hofer from OMV $\mathrm{GmbH}$ for supporting us with his knowledge, funding, ideas, and sample materials throughout the years.

Conflicts of Interest: The authors declare no conflict of interest. The funders had no role in the design of the study; in the collection, analyses, or interpretation of data; in the writing of the manuscript, or in the decision to publish the results.

\section{References}

1. Plasticseurope. Available online: https://www.plasticseurope.org/ (accessed on 13 October 2020).

2. Kumar, S.; Panda, A.K.; Singh, R.K. A review on tertiary recycling of high-density polyethylene to fuel. Resour. Conserv. Recycl. 2011, 55, 893-910. [CrossRef]

3. Ragaert, K.; Delva, L.; Van Geem, K. Mechanical and chemical recycling of solid plastic waste. Waste Manag. 2017, 69, 24-58. [CrossRef]

4. Ignatyev, I.A.; Thielemans, W.; Vander Beke, B. Recycling of Polymers: A Review. ChemSusChem 2014, 7, 1579-1593. [CrossRef] [PubMed] 
5. $\quad$ Ragaert, K.; Hubo, S.; Leite, L.; Martins, C. Evaluation of post-industrial and post-consumer polyolefin-based polymer waste streams for injection moulding. In Proceedings of the 6th Polymers \& Mould Innovations International Conference, Guimaraes, Portugal, 10-12 September 2014; pp. 201-206.

6. Kranzinger, L.; Pomberger, R.; Schwabl, D.; Flachberger, H.; Bauer, M.; Lehner, M.; Hofer, W. Output-Oriented Analysis of the Wet Mechanical Processing of Polyolefin-Rich Waste for Feedstock Recycling. Waste Manag. Res. 2018, 36, 445-453. [CrossRef] [PubMed]

7. Bauer, M.; Lehner, M. Review of post-consumer plastic preparation in Austria and new approaches for feedstock recycling. In Proceedings of the CSIR-Indian Institute of Petroleum (IIP) (Hrsg.): 7th International Symposium on Feedstock Recycling of Polymeric Materials (7th ISFR 2013), New Delhi, India, 23-26 October 2013; pp. 1-2.

8. Kunter, A.; Wellacher, M. Neue Entwicklungen bei der Ersatzbrennstoffaufbereitung. In Proceedings of the 10th Recy \& DepoTechConference, Leoben, Austria, 3-5 November 2010; Chair of Waste Processing Technology and Waste Management: Leoben, Austria, 2016; pp. 653-656.

9. EC (European Commission). EC (European Commission): Proposal for the Directive 94/62/EG of the European Parliament and of the Council 5 December 2015 on Packaging and Packaging Waste; EC (European Commission): Brussels, Belgium, 2015.

10. Tukker, A. Plastics Waste: Feedstock Recycling, Chemical Recycling and Incineration; Smithers Rapra Technology: Shrewsbury, UK, 2002.

11. Bauer, M.; Lehner, M.; Hofer, W. Prozesskette zum Stofflichen Recycling von Kunststoffabfällen, "Berg- und Hüttenmännische Monatshefte (BHM)"; Austrian Society for Metallurgy and Materials (ASMET) and Bergmännischer Verband Österreich (BVÖ): Leoben, Austria, 2002; pp. 246-251.

12. Kranzinger, L.; Pomberger, R.; Schwabl, D.; Bauer, M. Quo vadis Kunststoffrecycling-Bestandsaufnahme der polyolefinen Kunststoffe in der österreichischen Abfallwirtschaft. In Proceedings of the 13th Recy \& DepoTech-Conference, Lezoben, Austria, 8-11 November 2016; Chair of Waste Processing Technology and Waste Management: Leoben, Austria, 2016; pp. 583-588.

13. Schwabl, D.; Flachberger, H.; Kranzinger, L.; Bauer, M.; Hofer, W. Innovatives Verfahren zur Anreicherung von PolyolefinKonzentraten aus industriellen Reststoffströmen zum Zwecke einer stofflichen Verwertung. In Proceedings of the 10th "Recycling und Rohstoffe" Conference, Berlin, Germany, 6-7 March 2017; Thomé-Kozmiensky, K.J., Goldmann, D., Eds.; TK-Verlag: Berlin, Germany, 2017; pp. 199-218.

14. Bauer, M.; Lehner, M.; Schwabl, D.; Flachberger, H.; Kranzinger, L.; Pomberger, R.; Hofer, W. Sink-Float Density Separation of Post-Consumer Plastics for Feedstock Recycling. Mater. Cycles Waste Manag. 2018. [CrossRef]

15. Strzalkowski, J. Inbetriebnahme der Schwingesetzmaschine SK 3-10 von Siebtechnik mit Primärem sowie Sekundärem Aufgabegut. Master's Thesis, Chair for Mineral Processing, Montanuniversitaet Leoben, Leoben, Austria, 2017.

16. Schwabl, D.; Flachberger, H.; Kranzinger, L.; Bauer, M.; Hofer, W. Weiterentwicklung eines nassmechanischen Aufbereitungsverfahrens für Altkunststofffraktionen. In Proceedings of the 13th Recy \& DepoTech-Conference, Leoben, Austria, 8-11 November 2016; Chair of Waste Processing Technology and Waste Management: Leoben, Austria, 2016; pp. 173-178.

17. Pretz, T.; Feil, A. Ungenutzte Potentiale in der Abfallwirtschaft. In Proceedings of the 14th Recy \& DepoTech-Conference, Leoben, Austria, 14-16 March 2018; Chair of Waste Processing Technology and Waste Management: Leoben, Austria, 2018.

18. Thomè-Kosmiensky, K.J. Thermische Abfallbehandlung; EF-Verlag für Energie- und Umwelttechnik GmbH: Berlin, Germany, 1994.

19. Kranert, M.; Cord-Landwehr, K. Einführung in die Abfallwirtschaft. 4., Vollständig Aktualisierte und erw; Aufl. Wiesbaden; Vieweg+Teubner Verlag/GWV Fachverlage: Wiesbaden, Germany, 2010.

20. Peter, M.S.; Timmerhaus, K.D.; West, R.E. Plant Design and Economics for Chemical Engineers; McGraw-Hill Chemical Engineering Series; McGraw-Hill: New York, NY, USA, 2003.

21. Bauer, M.; Lehner, M. Abtrennung von Polyolefinen aus kunststoffreichen Abfallströmen mittels NIR-sensorbasierten Sortiertechnologie und Sortierzentrifuge. In Proceedings of the 9th Minisymposium der Verfahrenstechnik, Leoben, Austria, 17-18 April 2013; Chair of Process Technology and Environmental Protection: Leoben, Austria, 2013; pp. 92-96.

22. Schwabl, D.; Bauer, M.; Peyha, M.; Lehner, M. Überführung eines nass-mechanischen Aufbereitungsverfahrens für Altkunststoffe in den Pilotmaßstab. In Proceedings of the 15th Recy \& DepoTech-Conference, Leoben, Austria, 18-20 November 2020; Chair of Waste Processing Technology and Waste Management: Leoben, Austria, 2020; pp. 129-134. 